\title{
A INFLUÊNCIA DA RESPONSABILIDADE SOCIAL CORPORATIVA NO COMPORTAMENTO dO ESTUDANTE DE CIÊNCIASCONTÁBEIS
}

\author{
Edvalda AraújoLeal \\ MestreemCiênias Contábeis eAtuaniais \\ pedaUnivessidadeFedal deUbelânda \\ etvaldaleal@bol.combr
}

\author{
Cíntia Rodrigues de 0 liveira Medeiros \\ MestreemAdministraçãopda \\ UniversidadeFeckal deUbedânda \\ ántia@fappdi.edubr \\ Jacquelaine Florindo Borges \\ MestreemAdministraçãopda \\ UniversidadeFederal deUberlânda \\ jacbarges@ud.combr
}

\section{RESUMO}

A profunda-se 0 debate da comunidade acadêmica sobre a responsabilidade social e a ética no âmbito das organizações, e cresce na comunidade de negócios o questionamento sobre "se" e "como" as práticas de responsabilidade social (RS) influenciam no desempenho das empresas. Este artigo analisa a Responsabilidade Social Corporativa (RSC) na perspectiva do estudante de Ciências Contábeis. É um estudo de natureza quantitativa que busca mensurar a importância da responsabilidade social corporativa (RSC) para os estudantes do curso de graduação em Ciências Contábeis da cidade de Uberlândia, face à emergência de um novo perfil desse profissional. A pesquisa utiliza o método surveypara identificar como os estudantes compreendem a RC e como esta influencia o seu comportamento. As conclusões indicam contradições e ambigüidades relacionadas ao modo como os estudantes de Ciências Contábeis compreendem a RSC e como esta influencia o seu comportamento, ealertam a academia para a necessidade de inserir o tema em seus currículos.

Palavras-chave: Responsabilidade Social. Estudantes. Ciências Contábeis.

\section{ABSTRACT}

Therehas ben intenæedbatewithin theacademiccommmityabat sodial responsibility, and organizational thics Likenise, thebusiness commuityhasinmeasingybeninquiningabat "if" and "how" social responsibility (SR) pradices affect the peffomance of companies Thisartideanalyzes CorparateSocial Responsibility (CSR) through the perspetive of Accountangy studants This study has a quantitativenaturewhichattempts tomeasuretheimpatance of CorparateSocial Responsibility(CSR) toundargaduate A countany studants in the town of Ubelândia dueto the emergene of a newprofile of the accounting professional. The rearch was conducted through a surveymthod in ader toidantify howstudents undestand SR, and howit influenes their behavior. Condusions show that therearecontradidions as well asambigities rdated to howA cauntany students undestandCSR, and howit influenes their behavior. They also show theneed to inset thetopic in acadenicamiaula.

Key words: Social Responsibility. Students Accuntang. 


\section{INTRODUÇÃO}

Ao mesmo tempo em que se aprofunda o debate da comunidade acadêmica sobre a responsabilidade social e aética no âmbito das organizações, cresce na comunidade de negócios o questionamento sobre "se" e "como" as práticas de responsabilidade social (RS) influenciam no desempenho das empresas. A relevânciaqueas organizaçõesadquiriram na sociedade como provedoras de bens e/ ou serviços, acabou por apontá-las, também, como grandes consumidoras de recursos e, consequentemente, geradoras e causadoras do agravamento de problemas sociais e ambientais. Nesse contexto, estudos sobre RS tomaram vulto, fomentando o surgimento de diversas teorias, abordagens eterminologias (BAKKER; GROENEWEGEN; HOND, 2005; 2006; CARROL, 1979; 1991; 1999; GARRIGA; MELÉ, 2004; LOCKETT, MO O N, VISSER, 2006; WIND SO R 2006) que deram um novo contorno às discussões sobre o papel das empresas na sociedade contemporânea.

$\mathrm{O}$ interesse de pesquisadores, professores e profissionais da área de Ciências Contábeis pelo tema também é crescente, 0 queéjustificável mediante a afimmação de Iudícibus (2004) quanto ao papel que a contabilidade desempenha. Segundo esse autor, o principal objetivo da contabilidade é fornecer informações financeiras e econômicas a seus usuários de forma a contribuir para que a tomada de decisão seja feita a partir de análises quelhe dão sustentação. O s escândalos corporativos que emergiram em âmbito global nos anos 80 e 90 (ADLER, 2002; ZAHRA; PRIE M; RASHEED, 2005) geraram uma grande crise de confiança da sociedade e de investidores quanto à natureza e à amplitude das informações fornecidas sobre a avaliação de riquezas. Nesse contexto, o papel do contador ultrapassa os limites da avaliação das riquezas monetárias, e avança no sentido de fornecer informações que vão além, tais como a avaliação do patrimônio ambiental e a avaliação da geração da riqueza social.

Assim, o objetivo que orienta o presente estudo é mensurar a importância da responsabilidade social corporativa (RSC) para os estudantes do curso de graduação em Ciências Contábeis da cidade de Uberlândia, face à emergência de um novo perfil desse profissional. De que forma eles se posicionam quanto à importância da ética e da responsabilidade social empresarial? Como os estudantes de Ciências Contábeis se posicionam diante desse assunto?

Inicialmente, este artigo considera questões importantes do debateacerca da responsabilidade social corporativa, o Balanço Social como instrumento para apresentação das ações de responsabilidade social e o papel dos profissionais contábeis nesse novo contexto organizacional; em seguida, apresenta a metodologia de pesquisa. 0 s resultados do estudo, apresentados na sequência, mostram contradições e ambiguidades relacionadas ao modo como os estudantes de Ciências Contábeis compreendem aRSC e como elainfluencia o seu comportamento. Na seção final, apresentam-se a conclusões eimplicações da pesquisa.

\section{REFERENCIAL TEÓRICO}

0 referencial teórico deste estudo está fundamentado em conceitos chave, os quais serão elucidados por orientarem as perspectivas analíticas contidas na seção de resultados e discus- sões. Portanto, serão abordados conceitos e dimensões de estudo sobre a responsabilidade social corporativa, o papel do profissional contábil nesse contexto e também será visto o balanço social utilizado por empresas para disponibilizar informações sobre como a empresa considera as questões sócioambientais.

\subsection{Contextualização da Responsabilidade Social Corporativa}

Os argumentos contra e a favor da RSC, conforme Amaeschi e Adi (2006), podem ser agrupados em três perspectivas: (a) shardholdes argumenta a favor da responsabilidade econômica e legal da empresa; (b) stakdhddas defende que diferentes grupos de interesse podem influenciar ou serem influenciados pela realização dos objetivos da companhia; e (c) sociedade, em que a idéia central é que existe um contrato social entre a sociedade e o mundo dos negócios que regula as punições e as recompensas do comportamento corporativo.

A discussão entre a perspectiva de sharehddase a teo ria dos stakehddasé central quando o assunto é RC. A primeira perspectiva teve como principal defensor Friedman (1970), que reconheceu como prioridade da firma a sua responsabilidade por maximizar os lucros dos acionistas seguindo as leis. A segunda perspectiva, conforme Freeman $(1984,1999)$ e Freeman e Philips (2002), defende que o sucesso da organização depende dos relacionamentos que ela mantém com os indivíduos ou grupos chave que podem afetar ou serem afetados pela realização dos objetivos organizacionais. $\mathrm{Na}$ literatura relativa ao tema, a visão sócioeconômica tem prevalecido (BROWN; DACIN, 1997; SEN; BHATTACHARYA, 2001; ELLEN, MOHR, WE BB, 2000). D e acordo com essa abordagem, a empresa estará cumprindo com sua responsabilidade social na medida em que proporciona uma melhoria nas condições de vida da sociedade, atendendo a seus desejos e necessidades (MURRAY; MONTANARY, 1986).

G arriga e Melé (2004) agnuparam as principais teorias de RSC em quatro grupos: (a) as teorias instrumentais (relacionadas à função de adaptação ao ambiente); (b) as teorias políticas (relacionadas à função de atingir objetivos); (c) as teorias integradoras (relacionadasà função de integração); $\mathrm{e}(\mathrm{d})$ as teorias éticas (relacionadas à função de manutenção dos padrões culturais e valores ou latência). As teorias instrumentais de RSC abarcam as abordagens que enfatizam a realização de objetivos econômicos por meio de atividades sociais. Para alguns autores, a responsabilidade da empresa é maximizar o valor para 0 acionista(FRIED MAN, 1970); para outros, é uma estratégia para obter vantagem competitiva (PO RTER; KRAMER, 1999; 2002). Nesse mesmo grupo insere-se a perspectiva de que as ações socialmente responsáveis é um instrumento para criar e manter uma imagem positiva da empresa perante o público interno e externo.

No segundo grupo, incluem-se as teorias que enfatizam 0 poder social das corporações, especificamente nas suas relações com a sociedade, considerando que as grandes corporações adquiriam enorme poder e passam a ter responsabilidades naarena política. $O$ pressuposto é a existência de um contrato social implícito entre sociedade e o mundo dos negócios(DONALDSON; DUNFEE, 1994). Também nesse grupo inserem-se as aborda- 
gens sobre a cidadania corporativa (empresa-cidadã) que discutem os direitos, as responsabilidades e as possíveis parcerias entre empresas e sociedade (GARRIGA; ME LÉ, 2004).

$O$ terceiro grupo é constituído por teorias integradoras que enfatizam a idéia de que as empresas dependem da sociedade para a sua existência, sua continuidade e seu crescimento. Assim, as demandas sociais são consideradas o sustentáculo para que as empresas obtenham certa legitimidade e algum prestígio, visto que ao atender tais demandas, cria-se o espaço de interação entre sociedade e mundo dos negócios. Garriga e Melé (2004) ressaltam que, dessa maneira, as corporações são dirigidas de acordo com os valores da sociedade naquele contexto específico, focalizando sobre as demandas sociais que garantem sua legitimação social e prestígio perante a sociedade. Nesse grupo, as perspectivas mais representativas são a teoria dos stakddddes (MITCHELL; AGLE; WOOD, 1997) e a abordagem da pefommancesocial corporativa (CARRO L, 1979, 1991, 1999).

$\mathrm{O}$ quarto grupo de teorias abrange os estudos que têm como base os princípios que expressam os direitos universais e o desenvolvimento sustentável. 0 pressuposto desse grupo é que os valores éticos permeiam o relacionamento entre negócios e sociedade, o que leva as companhias a aceitarem responsabilidades sociais como um dever e um compromisso ético. A abordagem de Freeman (1984) sobre a teoria dos stakehddes é uma abordagem ainda não consolidada nesse sentido, cujas bases filosóficas pressupõem o bem comum da sociedade como valor orientador da RSC (GARRIGA E ME LÉ, 2004).

A compreensão da RSC proposta por Carroll $(1979,1991)$, a partir da construção de um modelo piramidal conforme a natureza da RSC, destaca quatro elementos constituintes, da base para o topo: econômico, legal, ético e discricionário ou filantrópico. A categoria econômica está na base do modelo piramidal visto que ser lucrativa, maximizar vendas, minimizar custos e ter uma política de dividendos constitui o cerne dessa dimensão da qual dependem todas as outras responsabilidades da firma. A responsabilidade legal corresponde ao cumprimento das leis e à adoção de todas as regulamentações, coexiste com a responsabilidade econômica como um preceito fundamental do sistema de livre mercado. A responsabilidade ética diz respeito às práticas e às ações esperadas ou proibidas pelos membros de uma sociedade, estando relacionada à honestidade, à justiça e ao respeito aos direitos. A filantropia está no topo da pirâmide, é uma resposta voluntária e discricionária da firma às expectativas e aos desejos da sociedade de que as companhias sejam "boas cidadãs corporativas" (CARRO L; BUCHHO LTLZ, 2003).

Outra abordagem sobre a RC é aquela que predomina nas instituições criadas com o objetivo de assessorar as companhias na elaboração de relatórios e na divulgação das ações sociais e ambientais que empreendem. A G lobal Reporting IniciativeGRI (2007) é uma instituição independente que colabora com 0 Programa Ambiental das Nações Unidas (United Nations Environmental Programme - UNEP), desenvolvendo e disseminando globalmente as diretrizes mais adequadas à elaboração de relatórios de sustentabilidade para as organizações que desejam relatar e divulgar o seu desempenho em três vertentes: econômica, social e ambiental. Uma gestão sustentável, segun- do essa instituição, é aquela que reconhece e valoriza as principais partes interessadas, que são os diversos públicos queintervêm de forma ativa na construção do valor da empresa, tais como acionistas, consumidores, fornecedores, organizações nãogovernamentais, governo, etc. 0 conceito de sustentabilidade está relacionado a uma "nova" visão global das empresas que passam a gerir de forma integrada a geração de valor no âmbito econômico, social e ambiental.

Nessa perspectiva, a atividade dos negócios deveria incorporar benefícios sociais juntamente com os ganhos econômicos que a empresa busca. Assim, é relevante caracterizar a importância do ambiente institucional e sua relação com a performance e a conduta dos agentes econômicos num determinado mercado. 0 contexto institucional, em última análise, é que balizará em cada situação a natureza, o grau e o tipo de conduta socialmente responsável que a empresa deverá manifestar, mantendo a sua função básica de criação de valor e 0 aumento da riqueza para os seus acionistas.

Por fim, éimportante destacar que a RSC éalvo de críticas e muito ceticismo. Jones (1996), a partir de uma perspectiva marxista-institucionalista, critica a coerência teónica, a relevância empírica, a viabilidade normativa e as implicações relacionadas aos argumentos da RS. 0 autor enfatiza que 0 conceito e 0 discurso da RS são viáveis somente na ausência de uma compreensão historicamente fundamentada da lógica da economia política capitalista, e o tipo de organização e a consciência que a orienta. Nesse sentido, Jones (1996) afirma que a RS como conceito se torna um BandAidsobre as graves cicatrizes capitalistas, e como discurso se constitui em uma ideologia influente com implicações materiais para os grupos de stakedoldkrao buscar a legitimação do statusquosocietal, pois se dirige mais para os sintomas do que para as causas.

As críticas à RS nos levam a questionar até que ponto ela, sendo uma resposta das companhias à crise de confiançainstalada no final do século XX e começo do século XXI, constitui um caminho de transformação ou um caminho em que as companhias buscam, mais uma vez, reafirmar o seu papel no ambiente sóciopolítico.

\subsection{0 profissional contábil e a responsabilidade social}

A avaliação da responsabilidade social das empresas é importante para que os tomadores de decisão nas empresas e stakdhddassaibam como estão as organizações de seu interesse frente aos aspectos sócioambientais. O Balanço Social, ou outra publicação que disponibilize informações sócioambientais de uma organização, é uma das ferramentas pioneiras para sintetizar e disponibilizar as informações sobre como a empresa vem lidando com essas questões.

Balanço Social, Relatório de Sustentabilidade Empresarial, Balanço Social Corporativo, Relatório Social e Relatório SocialA mbiental são alguns dos nomes utilizados pelas empresas, pelos especialistas e acadêmicos para denominar o material informativo sobre a situação da empresa em relação aos problemas sociais e ambientais. Publicações desse tipo tornaram-se populares no Brasil e no mundo, nos últimos anos, principalmente a partir da década de 1980 (ADAMS, HILL \& RO BE RTS, 1998; 
SIQUEIRA \& VIDAL, 2002). Diferente dos relatórios anuais das empresas que visam divulgar informações principalmente aos acionistas, o conceito básico do balanço social é difundir informações que interessem a todos os stakeddders Assim, o balanço social deve conter informações qualitativas e quantitativas sobre o modo como a empresa desempenha sua função social e ambiental, bem como sua relação com os diversos stakedddas

As informações contidas nos balanços sociais variam devido a vários fatores, tais como a atividade, o tamanho, o tipo gerencial e o contexto regional e temporal em que a empresa está inserida (ADAMS, HILL; ROBERTS, 1998; LEWIS; UNERMAN, 1999), dependendo, também, do interesse e da capacidade que a empresa tem em produzi-los, e o tipo depressão que sofre por parte dos stakedddas Na década de 1970, os balanços sociais das empresas americanas dirigiam maior atenção ao emprego de minorias, já que era um tema de relevância na época naquele país; no Canadá, a ênfase foi dada aos benefícios trabalhistas (LEWIS; UNERMAN, 1999). Mesmo estando dentro de um contexto de integração forte como a União Europeia, os conteúdos e as formas dos balanços sociais dos países europeus variam significante-mente (ADAMS, HILL; RO BERTS, 1998). Também há uma diferença entre os balanços sociais de empresas dessespaíses e do Brasil (FREIRE; RE BO UÇAS, 2001).

Também tem surgido um movimento de integração global entre os diversos movimentos e as demais organizações nacionais e regionais que lidam com a questão de responsabilidade sócioambiental. No âmbito do balanço social, existe uma tentativa de integração global das diversas tendências de publicações de informações sócioambientais por meio da Global Reporting Initiative - GRI (GRI, 2007). O GRI tenta difundira importância de se publicar balanços sociais e uma padronização mínima que os balanços devem ter para que sejam de utilidade aos diferentes stakehddess

Diante desse contexto, a profissão do contador sofre mudanças quanto aos conteúdos, conhecimentos e às habilidades necessárias para o desempenho de suas funções. A informação gerada adequadamente e evidenciada de forma oportuna e não enviesada é que gera valor à sociedade. Numa visão clássica, a Contabilidade é um sistema de informação e avaliação cujo propósito é fornecer aos seus diversos usuários demonstrações e análises de natureza econômica, financeira, física, de produtividade, social e ambiental, relacionadas à entidade objeto de contabilização (IUD ÍCIBUS; MARIO N, 2002).

Dessa maneira, Ribeiro (1992, p. 68) observa que "um dos grandes entraves da evolução da Contabilidade de Responsabilidade Social ou, simplesmente, Contabilidade Social, é a resistência do meio empresarial em reconhecer sua responsabilidade perante a sociedade, dado que isto viria onerá-los". 0 empenho da contabilidade em responder aos desafios que transcendem os aspectos econômico-financeiros, levou à busca de uma nova demonstração, de cunho social, que permite identificar e demonstrar os impactos recebidos e causados pelas entidades, relacionados ao ambiente social e ecológico. Evidentemente que a mensuração desses impactos não é uma tarefa muito fácil, estando envolta em problemas metodológicos ainda distantes de serem superados. Somando-se a isso, tem-se 0 fato de que a divulgação de informação de natureza social é voluntária. Esses fatores podem contribuir para o desenvolvimento de informação social de maneira desordenada, em que a entidade informa apenas o que lhe convém, valendo-se de critérios e medidas particulares variáveis e discutíveis (TINO CO, 2001).

Segundo Kroetz (2000, p. 45), "é nesse contexto que surge a contabilidade com sua cultura e tecnologia, oferecendo, conjuntamente, aos profissionais da área um arsenal capaz de gerar, demonstrar e analisar o perfil da responsabilidade social/ ecológico das entidades".

As implicações da adoção de uma postura ética e socialmente responsável pelas empresas têm sido amplamente estudadas. Diversos resultados de pesquisas sugerem que os consumidores tentem a valorizar a empresa socialmente responsável (MURRAY; VO GEL, 1997; CREYER; ROSS,1997; MO HR et al. 2001) e isso pode influenciar positivamente seu comportamento de compra (BROWN; DACIN, 1997; SEN e BHATTACHARYA, 2001); ou negativamente, caso a empresa seja vista como antiética (BROWN; DACIN, 1997; SERPA; FURNEAU, 2004). O utros resultados apontam para o pouco ou nenhum impacto da postura de responsabilidade social corporativa no comportamento do consumidor (CARRIGAN E ATTALLA, 2001; URDAN E ZUÑIGA, 2001). Há resultados controversos também no que se refereà correlação entre responsabilidade social e lucratividade (AUPPERLE; CARRO LL; HATFIELD, 1985 ; McGUIRE; SUNDGREN; SCHENEEWEIS, 1988).

Assim, o profissional contábil torna-se responsável pelo aprimoramento das atuais demonstrações contábeis, agregando informações sociais e ecológicas às informações financeiras e patrimoniais disponibilizadas. D essa forma, proporciona à sociedade uma alternativa de análise e avaliação da ação das entidades públicas e privadas quanto ao uso dos recursos naturais disponíveis eà eficácia da gestão patrimonial, com os respectivos resultados acrescentados ou adicionados aos trabalhadores ou às comunidades em geral (TINO CO , 2001).

Mazzioni (2005) observa que o Balanço Social pode ser visto como um demonstrativo oriundo da contabilidade representativo de um avanço e da evolução de um sistema desenhado para a elaboração de peças contábeis de natureza econômica e financeira. 0 Balanço Social está associado, portanto, à transformação ocorrida na sociedade e a uma nova postura adotada pelas entidades de modo geral. A ética empresarial e a responsabilidade social passaram a ser tema central das discussões e muitas empresas começaram a investir em áreas sociais.

Paraalcançar o estágio desejado, a contabilidade precisou e precisa constantemente dotar-se de conhecimentos, de ferramentas, enfim, de todo um arcabouço conceitual, para bem poder responder a seus usuários internos e externos. Para dar maior visibilidade e publicidade às ações sociais e ambientais realizadas pelas empresas, surgiu a necessidade e 0 interesse em tomá-las públicas, divulgar a imagem da empresa com relação à sua atitude ética com as questões sociais, para os clientes, os fornecedores e o governo. Assim, utiliza-se de relatórios regulares, tratado nos últimos anos de Balanço Social (TINOCO, 2001; FREIRE; REBO UÇAS, 2001). 
Sucupira (2001) reconhece a origem contábil do Balaço Social, porém imputa-lhe um caráter diferenciado, ao admitir que não deva ser visto como um demonstrativo meramente contábil, mas como uma forma de explicitar sua preocupação com o cumprimento de sua responsabilidade social. É por meio da contabilidade que as entidades divulgam aos seus diferenciados usuários o desempenho econômico, financeiro, ambiental, social e de responsabilidade corporativa e pública.

0 processo evolutivo do sistema contábil ficará mais perceptível ao conjunto amplo da sociedade a partir de uma adesão mais consistente do profissional contábil em adotá-lo como elemento importante na prestação de contas à sociedade. Niyama (2005) compara a contabilidade à linguagem dos negócios, em que os principais agentes econômicos buscam informações sobre a situação da empresa ea avaliação de riscos para se realizar investimentos. A importância da contabilidade ultrapassou as fronteiras, deixando de ter sua utilidade limitada ao campo doméstico para servir de instrumento no processo decisório em nível internacional, principalmente, no atual cenário de globalização dos mercados (NIYAMA, 2005).

Ao mesmo tempo em que a contabilidade passa a ser discutida quanto ao papel informativo que desempenha no âmbito da gestão empresarial, o seu principal agente, o contador, não fica à margem desse processo. Nesse novo ambiente, os contadores, com vistas à efetiva contribuição para o processo de geração de valor às organizações, devem incorporar novas habilidades pessoais, desenvolver a capacidade de entendimento do negócio e adotar uma postura mais empreendedora, ética, e que atenda a responsabilidade social (SUCUPIRA, 2001).

Apesar da ausência de estudos aprofundados sobre o ensino da Responsabilidade Social para os estudantes de Ciências Contábeis, é notória a relevância do assunto para a formação desses profissionais, visto serem eles os futuros provedores dos diversos stakdhddasde informações a respeito das operações e do desempenho das organizações. A difusão de informação que acrescenta valor à entidade (que deve ser tratada como bem público) é um ato de responsabilidade social do profissional contábil que, através do desenvolvimento das técnicas contábeis, oferece sua contribuição para o desenvolvimento econômico e social.

\section{PROCEDIMENTOS METODOLÓGICOS}

Este estudo consiste em uma pesquisa de campo cujo objetivo é mensurar a importância da responsabilidade social corporativa (RSC) para os estudantes do curso de graduação em Ciências Contábeis da cidade de Uberlândia. É uma pesquisa de natureza quantitativa, realizada em duas instituições de ensino, uma pública e outra particular, que considera as posições dos estudantes em relação às três dimensões da RS: econômica, social e ambiental. E ssas dimensões estão presentes nos relatórios sociais de grandes companhias, a partir do modelo mundialmente difundido pela Global Reporting Iniciative- GRI (2007).

0 método de procedimento utilizado foi o Survey, a partir de questionário autopreenchido aplicado em duas Instituições de Ensino Supenior (IE S) da cidade de Uberlândia: Faculdade Politécnica de Uberlândia (instituição privada) e Universidade Federal de Uberlândia (instituição pública). 0 públicoalvo foi o estudante de graduação do curso de Ciências Contábeis.
Inicialmente, foi realizado um pré-teste com um total de 20 questionários aplicados nas duas instituições. 0 questionário foi aplicado para $20 \%$ dos estudantes presentes em cada sala, em Junho de 2006, na FaculdadePolitécnica de Uberlândia(FPU) e, em Agosto de 2006, na Universidade Federal de Uberlândia (UFU). 0 total de questionários aplicados foi de 382, sendo 193 na FPU e 189 na UFU, considerando estudantes do curso de Administração e Ciências Contábeis. Todos os questionários foram recebidos, mas apenas 379 foram processados e analisados, três questionários foram anulados porque foram respondidos por alunos de outro curso que faziam uma disciplina do curso de Administração. Importante ressaltar que para este estudo foi considerada somente a amostra dos estudantes do curso de Ciências Contábeis, que totalizaram 76 questionários respondidos na FPU e 90 questionários respondidos na UFU.

Para a tabulação e a análise dos dados coletados na pesquisa de campo foi utilizado o sattwareSPSS, o que permitiu, além da obtenção da frequência das respostas, o cruzamento de dados entre o ciclo de estudos (ciclo básico e ciclo profissionalizante) ao qual o estudante pertence e a importância atribuída a RSC no momento da compra.

0 questionário utilizado por este estudo está estruturado em três partes: (a) a seção inicial em que se levanta o perfil dos estudantes pesquisados; (b) a segunda parte em que se colocam perguntas relacionadas à concepção dos estudantes sobre a responsabilidade corporativa; e, (c) a terceira seção de perguntas que busca identificar o modo como os estudantes se comportam em relação à RSC.

\section{APRESENTAÇÃO E ANÁLISE DOS DADOS}

A primeira parte do questionário teve como objetivo traçar um perfil dos respondentes. Na Tabela 1 está apresentada a distribuição de frequência para o universo de 824 estudantes do curso de Ciências Contábeis das instituições pesquisadas.

Tabela 1: Perfil dos respondentes

\begin{tabular}{l|ccccccc}
\hline & \multicolumn{3}{|c}{$F P U$} & \multicolumn{3}{c}{$U F U$} & \multicolumn{3}{c}{ TOTAL } \\
\hline & $\mathrm{n}$ & $\%$ & $\mathrm{n}$ & $\%$ & $\mathrm{n}$ & $\%$ \\
Universo da pesquisa & 370 & & 454 & & 824 & \\
(A) Total de respondentes & 76 & 100 & 90 & 100 & 166 & 100 \\
(B) Gênero & & & & & & \\
$\quad$ Feminino & 38 & 50,0 & 52 & 57,8 & 90 & 54,2 \\
$\quad$ Masculino & 38 & 50,0 & 38 & 42,2 & 76 & 45,8 \\
(C) Idade & & & & & & \\
$\quad$ Até 24 anos & 24 & 31,6 & 63 & 70,0 & 87 & 52,40 \\
$\quad$ De 25 a 35 anos & 38 & 50,0 & 25 & 27,8 & 63 & 38,0 \\
$\quad$ Acima de 36 anos & 14 & 18,4 & 02 & 2,02 & 16 & 9,6 \\
(D) Renda Pessoal & & & & & & \\
$\quad$ De 1 a 3 SM & 42 & 55,3 & 63 & 70,0 & 105 & 63,3 \\
$\quad$ De 4 a 6 SM & 23 & 30,3 & 13 & 14,4 & 36 & 21,7 \\
$\quad$ De 7 a 9 SM & 6 & 7,9 & 0 & 0 & 6 & 3,6 \\
$\quad$ De 10 ou + SM & 2 & 2,6 & 4 & 4 & 6 & 3,6 \\
$\quad$ Nenhuma & 3 & 3,9 & 10 & 11,1 & 13 & 7,8 \\
(E) Ciclo de estudos & & & & & & \\
$\quad$ Básico & 33 & 43,4 & 36 & 40,0 & 69 & 41,6 \\
$\quad$ Profissionalizante & 43 & 56,6 & 54 & 60,0 & 97 & 58,4 \\
(F) Instituição de Ensino & & & & & & \\
$\quad$ FPU & & & & & 76 & 45,8 \\
$\quad$ UFU & & & & & 90 & 54,2 \\
\hline
\end{tabular}

Fonte: Elaborado pelos autores 
A maioria (54,2\%) pertence ao sexo feminino; tem renda pessoal de 1 a 3 salários mínimos (52,4\%) e cursa 0 ciclo profissionalizante $(58,4 \%)$. Quanto à idade dos respondentes, embora a maioria $(52,4 \%$ ) pertença à faixa etária até 24 anos, na FPU isso não se confirma, estando a maioria $(50,0 \%)$ na faixa de 25 a 35 anos. E m relação à renda pessoal, também se observam diferenças entre instituições, quando se comparam, no total, as faixas + de $10 \mathrm{SM}(3,6 \%)$ e nenhuma renda (7,8\%). A FPU está mais distante na faixa de nenhuma renda, e a UFU mais próxima quanto à faixa + de $10 \mathrm{SM}$.

A segunda parte do questionário foi dividida em dois grupos de perguntas: o primeiro contém questões relacionadas com a concepção dos estudantes sobre a responsabilidade corporativa (Tabela 2); e o segundo contém questões relacionadas ao modo como os estudantes se comportam em relação a essa questão (Tabela 3). senta convergência com aqueles obtidos na questão sobre 0 aspecto mais importante da missão da empresa, em que a minoria $(9,02 \%)$ aponta para a dimensão econômica, ou seja, crescer e dar lucro para os acionistas.

O s resultados obtidos quanto à principal razão para uma empresa adotar práticas de responsabilidade social (Tabela 2) indicam que a maioria $(24,7 \%)$ dos respondentes considera que as empresas praticam a responsabilidade social para preservar a imagem e a reputação, seguida de conquistar a lealdade dos consumidores (22,9\%). Assim, a responsabilidade social, como 0 marketing social, torna-se um importante fator para as empresas obterem vantagem competitiva empresarial, pois elas passam a incorporar em suas políticas os interesses dos grupos de indivíduos (stakehdders) que a influenciam, conseguindo, assim, responder mais rápida e eficientemente às suas deman-

Tabela 2: A concepção de RC segundo os respondentes

\begin{tabular}{|c|c|c|c|c|c|}
\hline & \multirow{2}{*}{$\begin{array}{l}\text { FPU } \\
\%\end{array}$} & \multirow{2}{*}{$\begin{array}{l}\text { UFU } \\
\%\end{array}$} & \multicolumn{3}{|c|}{ Total \% (166) } \\
\hline & & & FPU & UFU & TOT \\
\hline \multicolumn{6}{|l|}{0 aspecto mais importante para a missão da empresa é: } \\
\hline Crescer e dar lucro aos acionistas & 2,6 & 14,4 & 1,2 & 7,8 & 9,0 \\
\hline Oferecer produtos com qualidade e preços competitivos & 39,5 & 37,8 & 18,1 & 20,5 & 38,6 \\
\hline Ajudar a desenvolver o país e preservar a natureza & 57,9 & 47,8 & 26,5 & 25,9 & 52,4 \\
\hline \multicolumn{6}{|l|}{$\begin{array}{l}\text { As práticas mais importantes que identificam uma empresa socialmente } \\
\text { responsável são: }\end{array}$} \\
\hline Práticas ambientais & 40,8 & 46,7 & 18,7 & 25,3 & 44,0 \\
\hline Práticas sociais & 34,2 & 34,4 & 15,7 & 18,7 & 34,3 \\
\hline Práticas econômicas & 14,5 & 7,8 & 6,6 & 4,2 & 10,9 \\
\hline Não respondeu & 10,5 & 11,1 & 4,8 & 6,0 & 10,8 \\
\hline \multicolumn{6}{|l|}{ As práticas de RSC contribuem para melhorar o bem-estar da sociedade } \\
\hline Sim & 100 & 98,9 & 45,8 & 53,6 & 99,4 \\
\hline Não & - & 1,1 & 0,0 & 0,6 & 0,6 \\
\hline \multicolumn{6}{|l|}{ A responsabilidade pelo desenvolvimento social do país é: } \\
\hline Do governo & 50 & 62,2 & 22,9 & 33,7 & 56,6 \\
\hline Das empresas & 19,7 & 23,3 & 9,0 & 12,6 & 21,7 \\
\hline D a sociedade civil & 28,9 & 14,4 & 13,2 & 7,8 & 21,0 \\
\hline Não respondeu & 1,3 & - & 0,6 & 0,0 & 0,6 \\
\hline \multicolumn{6}{|l|}{ A responsabilidade social empresarial é: } \\
\hline Uma exigência da sociedade & 63,2 & 51,1 & 28,9 & 27,7 & 56,6 \\
\hline Apenas um modismo & 1,3 & 3,3 & 0,6 & 1,8 & 2,4 \\
\hline Uma estratégia empresarial & 34,2 & 45,6 & 15,7 & 24,7 & 40,4 \\
\hline Não respondeu & 1,3 & - & 0,6 & 0,0 & 0,6 \\
\hline \multicolumn{6}{|l|}{$\begin{array}{l}\text { A principal razão para uma empresa adotar práticas de responsabilidade } \\
\text { social é: }\end{array}$} \\
\hline Imagem e reputação & 19,7 & 28,9 & 9,0 & 15,7 & 24,7 \\
\hline Otimizar os lucros & 2,6 & 6,7 & 1,2 & 3,6 & 4,8 \\
\hline Conquistar a lealdade dos consumidores & 23,7 & 22,2 & 10,9 & 12,0 & 22,9 \\
\hline Dedução de impostos & 19,7 & 22,2 & 9,0 & 12,0 & 21,1 \\
\hline Conviçcão do seu papel social & 22,4 & 16,7 & 10,3 & 9,1 & 19,3 \\
\hline E uma forma de desenvolver competências em seus funcionários & 10,5 & 1,1 & 4,8 & 0,6 & 5,4 \\
\hline Não respondeu & 1,3 & 2,2 & 0,6 & 1,2 & 1,8 \\
\hline
\end{tabular}

Fonte: Elaborado pelos autores

Conforme a Tabela 2, a empresa socialmente responsável é identificada, pela maioria (44,0\%) dos respondentes, como aquelas que praticam, principalmente, ações ambientais, seguida daquelas que praticam ações sociais (34,3\%) e, com menor participação, ações econômicas (10,9\%). Esse resultado apre- das. Como consequência, melhora a imagem institucional e amplia a lealdade e a confiança dos consumidores.

Porém, os respondentes, ao se posicionarem quanto ao significado da RC, 40,4\% responderam tratar-se de uma estraté gia empresarial, enquanto que a maioria $(56,6 \%)$ dos respon- 
dentes apontou ser uma exigência da sociedade. Essa perspectiva indica que a RS engloba toda e qualquer ação que uma organização deve ter para com a sociedade.

Ainda que 99,4\% dos estudantes tenham afirmado que a RC propicia o bem-estar da sociedade, isso não significa que eles percebam a RC como elemento de transformação social (JONES, 1996), pois a maioria deles atribui como principal razão para uma empresa adotar práticas e compromissos sociais é a preocupação com a própria imagem e reputação (24,7 \%); em segundo lugar, vêm aqueles (22,9\%) que acreditam que as companhias se comportam de maneira responsável para conquistar a lealdade dos consumidores.

Quando questionados acerca de qual fator é o mais relevante e tem mais influência sobre a sua decisão de compra (Tabela 3), os estudantes responderam que é a qualidade dos produtos ou serviços $(51,3 \%)$, além de um bom atendimento no momento da aquisição e da pós-venda $(18,1 \%)$, seguido por preço competitivo (13,2\%). A conduta ética e as práticas de responsabilidade social e ambiental surgem em quarto lugar para $12,1 \%$ dos estudantes; isso implica que, como consumidores, a maioria dos estudantes age pensando em suas próprias situações. É interessante, porém, que o mesmo percentual $(56,7 \%)$ dos estudantes afirme já ter adquirido produto de uma companhia motivado pelo fato de essa empresa ser socialmente responsável e, um percentual elevado, 42,7\% , afirme não ter orientado suas compras por essa questão, o que parece indicar que para esses estudantes a companhia deve ser responsável em âmbito ambiental e social, porque isso é bom para a sociedade em geral, enquanto eles decidem suas compras por razões econômicas. Trata-se de uma assustadora transferência de responsabilidade, considerando o perfil dos respondentes.

Q uanto aos resultados obtidos sobre o conhecimento dos estudantes acerca das companhias que praticam ações socialmente irresponsáveis, $48,2 \%$ diz conhecer organizações que se comportam desse modo, mas uma parte significativa ( $50,0 \%)$ não conhece nenhuma empresa que tenha praticado ações socialmente irresponsáveis. Tal fato exige reflexão sobre 0 interesse desses estudantes em relação ao assunto, haja vista a quantidade de fatos noticiados que associam empresas conhecidas a escândalos, fraudes e abuso de poder. 0 mesmo se aplica à resposta referente se já adquiriu produto motivado pelo fato de a empresa ser socialmente responsável: 56,7\% afirmam que sim e 42,7\% respondem que não. Em relação à maneira pela qual o estudante tomou conhecimento das ações sociais praticadas por empresas responsáveis, das quais eles já adquiriram produtos motivados pela responsabilidade da companhia: $28,9 \%$ no ato da compra, pelos selos ou por indicações no produto, 24,1 por meio de publicidade das empresas, e apenas $1 \%$ diz que se informou sobre a RC por interesse pessoal, enquanto $42,2 \%$ não tomou conhecimento das ações sociais praticadas por empresas responsáveis.

A análise entre instituições sobre a influência da RC no comportamento dos estudantes (Tabela 3) apresenta poucas discrepâncias em relação à maioria das questões. Vale destacar, entre os estudantes da FPU, por exemplo, a conduta ética e as práticas de responsabilidade social e ambiental como aspecto mais importante no momento da compra que obteve um percentual de
18,4\%, bem acima dafrequência conjunta (12,1\%). O utra variação entre a distribuição conjunta e os resultados por IE Sé o modo como os estudantes tomaram conhecimento das ações sociais praticadas por empresas socialmente responsáveis. ConformeTabela 3, a distribuição conjunta indica a divulgação por meio de selos de RS nos produtos como principal meio (28,9\%) pelo qual os estudantes identificam empresas socialmente responsáveis; tal comportamento predomina entre os estudantes da FPU $(31,6 \%)$, mas para os estudantes da UFU, o principal meio é a divulgação por meio da publicidade das empresas (30,0\%).

Quanto à preferência dos estudantes no momento da compra (Tabela 3), a maioria (68,7\%) indicou que escolheria produtos oriundos de empresas socialmente responsáveis em situações em que as características dos produtos sejam semelhantes e o preço seja equivalente. Ao analisar os resultados dessa questão, por IE S, observa-se uma discrepância quanto à distribuição conjunta. O s estudantes da UFU apresentam concordância bem maior $(77,8 \%)$ do que os estudantes da FPU $(57,9 \%)$. A preferência incondicional, ou seja, mesmo que as características dos produtos não sejam semelhantes ou o preço não seja o mesmo, obteve a concordância de 21,1\% de estudantes da FPU e somente 7,82\% da UFU. Esse resultado apresenta convergência em relação ao aspecto mais importante no momento da compra. A conduta ética eas práticas de responsabilidade social e ambiental são apontadas por apenas 12,1\% do total dos respondentes, e, 13,9\% não considerariam outros aspectos senão a responsabilidade social.

A maioria dos estudantes (62,0\%) indicou que as práticas que violam os direitos sociais e humanos são as que mais influenciam negativamente na sua decisão de compra, seguidas das práticas que envolvem fraudes e abuso econômico (13,8\%), sendo as práticas que agridem o meio ambiente de menor influência $(12,7 \%)$. Esse resultado apresenta contradições quanto à resposta para a primeira questão da Tabela 3.0 u seja, os estudantes atribuem à responsabilidade econômica maior importância para a sua decisão no momento da compra, mas, ao mesmo tempo, é aúltima questão que os fazem deixar de comprar de uma empresa. As respostas por IES, quando comparadas, apresentam convergências e algumas discrepâncias com os resultados da distribuição conjunta. Por exemplo, com relação às práticas que envolvem a violação dos direitos humanos os estudantes da UFU (62,2\%) e daFPU (61,8\%),já os estudantes da UFU deram mais importância às práticas que agridem 0 meio ambiente $(15,6 \%$ ) contra 9,3\% dos estudantes da FPU. 0 s estudantes daFPU atribuíram maior influência negativa às práticas fraudulentas com o objetivo de auferir benefícios econômi$\cos (18,4 \%)$ em relação aos estudantes da UFU (10,0\%).

\section{CONSIDERAÇÕESFINAIS}

As conclusões do estudo mostram contradições e ambiguidades relacionadas ao modo como os estudantes de Ciências Contábeis compreendem a RC e como a RC influencia o seu comportamento. Como evidenciado nos resultados desta pesquisa, os estudantes e futuros profissionais pesquisados entendem que o desenvolvimento social do País é uma atribuição governamental e que a sociedade tem pouco a fazer nesse 
sentido. Quanto à responsabilidade das companhias, todos concordam que ela é necessária para a construção de uma sociedade melhor. Todavia, para esses estudantes, no momento da compra, qualidade, atendimento e preço são os atributos mais importantes, e a minoria daria preferência aos produtos ou serviços de uma empresa considerando em primeiro lugara responsabilidade da companhia.

O utra evidência da pesquisa indica que o estudante trata de maneira contraditória as três dimensões da RC. Eles entendem que, por ordem de importância, a responsabilidade das companhias é: ambiental, social e econômica. Porém, as práticas mais importantes para que esse estudante deixe de comprar os produtos ou serviços de uma empresa, por ordem de importância, são: social, econômica e, por último, a ambiental. Um percentual significativo não conhece empresas que agem de formal irresponsável, e não adquiriu produtos ou serviços motivados pelo fato de a empresa ser socialmente responsável. E , a maioria que diz conhecer empresas que agem de forma responsável obteve esse conhecimento na divulgação por meio de selos de RS nos produtos e por meio de publicidade das companhias. Essa postura passiva e contraditória dos estudantes gera preocupação sobre o seu comportamento como o profissional que irá prover os diversos stakehddas, a respeito das operações e desempenho das entidades, não só relacionadas às informações financeiras, incluindo dados sociais e ambientais.

Tais evidências chamam a atenção paraa forma como os conteúdos de RSC estão sendo disseminados nas Instituições deEnsino Superior (IES), e servem de alerta para professores e instituições sobre o modo como auxiliar os estudantes a lidar com essa problemática. Destaca-se a necessidade de esforços mais consistentes que ampliem os estudos de como inserir, na educação formal do curso de Ciências Contábeis, orientação para atitudes éticas e para a consciência da responsabilidade social corporativa. $\mathrm{O}$ contador deve ser capaz de desenvolver, analisar e implantar sistemas de informação contábil e controle gerencial, exercendo com ética suas atribuições. Além disso, deve estar integrado com os problemas sociais e assumir uma postura de maior autonomia e participação na sociedade, pois será o responsável em aprimorar as atuais demonstrações contábeis, agregando informações sociais e ecológicas às informações financeiras e patrimoniais disponibilizadas à sociedade, como uma prestação de conta dos resultados acrescentados ou adicionados aos trabalhadores ou à comunidade em geral.

Nesse sentido, são sugeridas para futuras pesquisas duas possibilidades para preencher as lacunas existentes: primeiro, investigar as estruturas curriculares e ementas dos cursos de ciências contábeis com o propósito de verificar se possui conteúdos relacionados à responsabilidade corporativa; segundo, investigar o quão os docentes do curso de ciências contábeis têm condições de inserir, nos conteúdos ministrados, o entendimento do que seja a responsabilidade corporativa econômica, social e ambiental.

A influência da RC no comportamento dos estudantes de ciências contábeis, caracterizado pelas contradições e ambiguidades apresentadas neste estudo, constitui um alerta para os profissionais do ensino sobre como auxiliar os estudantes a lidar com essa problemática. A contabilidade como ciência social estruturada e com seu objeto de estudo delineado deve utilizar métodos e conceitos para alcançar resultados satisfatórios para as organizações, exercendo assim o seu verdadeiro papel de ciência do patrimônio, capaz de contribuir para o desenvolvimento da sociedade de um modo geral.

\section{REFERENNCIAS}

ADAMS, C. A.; HILL, W.; ROBERTS, C. B. Corporate social reporting practices in Western Europe; legitimating corporate behavior? The British Accounting Revien v. 30, n. 1, p. 1-21, 1998.

AD LER, P. Corporate scandals: It's time for reflection in business schools. A cadamy of Management Exeative, v. 18, n. 3, p. 148-150, 2002.

AMAESHI, K. M.; ADI, B. Reconstructing the corporate social responsibility construct in Utlish. Business Ethics a European Reiew, v.16, n.1, p. 3-18, 2006.

AUPPERLE, K. E.; CARROLL, A. B.; HATFIELD, J.D.An Empirical Examination of the Relationship Between Corporate Social Responsibility and Profitability. Academy of Management Joumal, V. 28, No. 2, p. 446-463, 1985

BAKKER, F. G.; GROENEWEGEN, P.; HOND, F. D. A bibliometric analysis of 30 years of research and theory on corporate social responsibility and corporate social performance. Business and Socidy, v. 44, n. 3, p. 283-317, 2005.

BROWN, T. J. e DACIN, P.A. The Company and the Product: Corporate Associations and Consumer Product Responses. Jaumal of Markeing Vol. 61, p. 68-84, 1997

CARRIGAN, Marylyn; ATTALLA, Ahmad. The Myth of the Ethical Consumer - D o Ethics Matter in Purchase Behavior? Jaumal of Consumer Markeing V. 18, Issue 7, p. 560-578, 2001.

CARRO LL, A. B. A Three-dimensional conceptual model of corporate social performance. Acadamy of Management Review v. 4, n. 4, p. 497-505, 1979.

. The pyramid of corporate social responsibility: toward the moral management of organizational stakeholders. Business Horizons v. 34, n.4, p. 39-39, 1991.

. Corporate social responsibility: evolution of a definitional construct. Business and Socidy, v. 38, n. 3, p. 268-295, 1999.

CARROLL, A. B.; BUCHHO LTZ, A. K. Corporate Citizenship: social responsibility, responsiveness, and performance. In. CARRO LL, A. B.; BUCHHO LTZ, A. K. Business \& Socidy: ethics and stakeholder management. O hio/ United States: Thomson Learning, 2004.

CREYER, E. H.; ROSS JR, W T. The Influence of Firm Behavior on Purchase Intention: Do Consumers Really Care About Business Ethics? Jaumal of Consumer Markeing V. 14, No. 6, p. 421-432, 1997.

D O NALD SON T.; DUNFEE, T.W. Towards a unified conception of business ethics: Integrative social contracts theory. Acadamy of Managenent Review. v.19, n. 2, p. 252-284, 1994

ELLEN, P.S.; MOHR, L. A.; WEBB, D. J. Charitable Programs and the Retailer: D o They Mix? Jarmal of Reailing V. 73, Issue 3, p. 393-406, 2000.

FREEMAN, R. Edward; PHILLIPS, Robert A. Stakeholder theory: a libertarian defense. Business Ethics Quartely, v.12, n.3, p.331-349, 2002. 
. D ivergent stakeholder theory. Acadamyof ManagmentReview v. 24, n. 2, 33-236, 1999.

FREIRE, F. S. \& REBOUÇAS, T. R. S. Uma D escrição Sucinta do Balanço Social Francês, Português, Belga e Brasileiro. In: SILVA, César A. T. \& FREIRE, Fátima S. (O rgs.), Balanço Social: Teara e Prática. São Paulo: Editora Atlas, 2001.

FRIED MAN, M. The social responsibility of business is to increase its profits. TheNewYork Tims Magazine, September 13, 1970.

GARRIG A, E.; MELÉ, D. Corporate Social Responsibility Theories; mapping the territory. Jourmal of Business Ethics v. 53, n.1-2, p.5171, 2004.

GRI - G lobal Reporting Initiative. Sustainability Reparting Guiddines onEconomic Environmental andSocial Peformance, Gldbal ReporingInitiative Disponível em: <www.gri.org>. Acesso em: 20 Nov. de 2007.

IUD ÍCIBUS, S. de; MARIO N, J. C. Introduçãoà teonia da contabilidade para o níved de graduaçãa 3. ed. São Paulo: Atlas, 2002.

.Teria da Contabilidade São Paulo: Atlas, 2004.

JONES, T. M.; Missing the forest for the trees: a critique of the social responsibility concept and discourse. Business and Socidy, v. 35, n.1, p. 7-41, 1996.

KROETZ, C. E. S. Balaņ̧o sodal: teoria e prática. São Paulo: Atlas, 2000.

LEWIS, L.; UNERMAN, J. ETHICAL RELATIVISM: A Reason for D ifferences In Corporate Social Reporting?, Critical Perspetives on Acounting v. 10, n. 4, p. 521-547, 1999.

LOCKETT, A.; MOON, J.; VISSER, W. Corporate social responsibility in management research: focus, nature, salience and sources of influence. Joumal of Management Studies, v. 43, n. 1, p. 115-136, 2006.

McGuiRE, J. B.; SUNDGREN, A. e SCHNEEWEIS, T. Corporate Social Responsibility and Firm Financial Performance. Academy of Managment Jaumal, Vol. 31, Isuue 4, p. 854-872, 1988. MITCHELL, R. K.; AG LE, B. R.; WO OD, D.J.; Toward a Theory of Stakeholder Identification and Salience: Defining the Principle of Who and What Really Counts. Academy of Management Review, v. 22, n. 4, p. 853-886, 1997.

MURRAY, Keith B.; MONTANARI, John R. "Strategic Management of the Socially Responsible Firm: Integrating Management and Marketing Theory". Academy of Management Review Vol. 11, No. 4, p. 815-827, 1986.

MURRAY, K; VOGEL, C M. Using a Hierarchy-of-Effects Approach to Gauge the Effectiveness of Corporate Social Responsibility to Generate Goodwill Toward the Firm: Financial Versus Nonfinancial Impacts. Joumal of Business Research, Vol. 38, p. 141-159, 1997.

NIYAMA, J. K. Contabilidade Intemacional. São Paulo: Atlas, 2005. PORTER, M. E.; KRAMER, M. R. Philanthropy's new agenda: creating value. Harvard Business Review v. 77, n. 6, p. 121-130, 1999.

. The competitive advantage of corporate philanthropy. Harvard Business Review v. 80, n. 12, p. 56-69, 2002.

RIBEIRO, M. de S. Contabilidade e mio ambiente 1992. $141 \mathrm{f}$. Dissertação (Mestrado em Ciências Contábeis) - Faculdade de Economia, Administração e Contabilidade, Universidade de São Paulo, São Paulo, 1992.

SEN, S. e BHATTACHARYA, C. B. D oes D oing G ood Always Lead to Doing Better? Consumer Reactions to Corporate Social Responsibility. Jaumal of Marketing Research, Vol. 38, p. 225-243, 2001.
SERPA, D. A. F.; FOURNEAU, L. F. O Consumidor Ético Brasileiro: Realidade ou Ficção? Amais.. XVII Congresso LatinoAmericano de Estratégia, Santa Catarina, 2004.

SIQUEIRA, J. R. M.; VIDAL, M. C. R. Mensuração do impacto social das empresas: Uma abordagem qualitativa aos balanços sociais brasileiros. Anais... XXXVII Congresso Latino-americano de Escolas de Administração (Cladea), Porto Alegre, 2002.

TINO CO, J. E.P. Balanç sodal: uma abordagem da transparência e da responsabilidade pública das organizações. São Paulo: Atlas, 2001.

SUCUPIRA, J. A. Ética nas empresas e balanço social. In: SILVA, C.A.T; FREIRE, F. de S. (O rg.). Balaņ̧o sodal: teoria e prática. São Paulo: Atlas, p. 117-133, 2001.

URDAN, A T.; ZUÑIGA, M. K. H.). A Influência da Responsabilidade Social nas D ecisões de Compra de Produtos de Conveniência. Anais.. do XXV Enanpad, 2001.

WIND SO R, D. Corporate social responsibility: threekey approaches. Joumal of Management Studies v. 43, n. 1, p. 93-114, 2006.

ZAHRA, S A; PRIEM, R.L.; RASHEED, A.A. The Antecedents and consequences of Top Management Fraud. Jaumal of Management. v. 31, p. 803-830, 2005. 
